\title{
An Innovative Strategy for Power System Restoration using Utility Scale Wind Parks
}

\author{
L. Seca, H. Costa, C. L. Moreira, J. A. Peças Lopes \\ The authors are with INESC_TEC and with FEUP; \\ Address: Campus da FEUP, Rua Dr. Roberto Frias, 378, 4200 - 465 Porto, Portugal; \\ E-mails: 1seca@inescporto.pt, ee06246@fe.up.pt, cmoreira@inescporto.pt, jpl@fe.up.pt
}

\begin{abstract}
This paper presents an innovative Power System Restoration (PSR) that exploits the flexibility offered by large offshore wind parks, in particular with HVDC connection with Voltage Source converter (VSC) technology, to support restoration following a black out in a typical transmission grid. Restoration sequences comparing different strategies in a VHV AC network with conventional generation (thermal units and hydro units) were implemented for two cases: with and without the participation of a large offshore wind farm in the restoration plan. In order to evaluate the benefit of using Utility scale Wind Parks to support PSR, a typical transmission network with all its models (including HVDC link with DC converter) was implemented in EUROSTAG simulation platform.
\end{abstract}

\section{Introduction}

Over the last years there has been a significant increase in the integration of renewable based energy sources in the electrical system, such as wind, solar and biomass. This new generation paradigm has been fostered by the "climate and energy package" (also known as the 20-2020 targets), that was agreed by the European Parliament and Council in December 2008 [1], establishing very ambitious targets for renewable energy integration in all EU countries.

In this context, renewable based Distributed Generation (DG) allows exploiting geographically dispersed renewable energy resources, leading to a new electric power system development paradigm. However, to accomplish the ambitious targets for 2020, there has been a significant investment in large wind farms (WF) connected directly to transmission networks. These large wind parks, both onshore and offshore, connected at very high voltage levels and with large installed capacities, are defined as Utility scale wind parks [2].

The large scale integration of renewable based energy sources has however a significant impact in power system operation. In effect, these large shares of variable energy sources replace conventional synchronous units (such as thermal), thus reducing system inertia as well as frequency and voltage regulation capabilities. This fact, together with the need of exploitation the network closer to its technical limits has exposed the power systems to vulnerabilities, being the worst consequence the occurrence of blackouts that may cover large geographical areas. Since electricity is a basic need in today's world, a blackout carries very large social and economic losses, thus requiring a way to achieve system restoration as fast as possible [3].

In the new generation paradigm, where conventional power stations are frequently out of service in order to accommodate large amounts of wind power injections, the number of generation units for the restoration phase can be limited due to the time constraints to its start-up and connection to the grid. In additional to typical units used in the initial phases of the restoration procedures (such as hydraulic or gas turbines), available resources such as wind generation, that currently offer enhanced control capabilities and thus high flexibility, can be a valuable resource to be integrated in the overall restoration procedure.

Power system restoration after a general blackout is a complex and time consuming task, which is very dependent on specific characteristics of the power system in analysis. Recent work has demonstrated the possibility of exploiting small scale distributed generation for restoration purposes in the distribution level [4-5]. At the transmission level, system operators develop specific restoration schemes that meet their particular needs. Power system conventional restoration procedures are usually developed before any emergency situation occurs, adopting heuristic approaches, which reflect human operators experience to deal with the problem. Furthermore, the size and specific characteristics of actual power systems precludes the definition of a universal methodology [6]. The restoration plan is defined step by step, based on pre-defined guidelines and operating procedures, sometimes exploiting decision support tools, which are an extremely valuable resource to assist system operators [7]. The restoration procedure is focused on the plant preparation for restart, network energization and 
system rebuilding. Depending on system characteristics, a choice must be made between a strategy of energizing the bulk network before synchronizing most of the generators or a strategy of restoring electrical islands that will be synchronized [8] afterwards.

Within conventional restoration plans, it is a common practice that DG and utility-scale renewable based energy sources are only reconnected when the grid is energized and present stable values of voltage and frequency. In order to create the technical conditions to allow a large scale integration of wind generation, Transmission System Operators (TSO) have been defining specific rules and conditions that WF should comply in order to be connected to the grid. Therefore, new WF behave as a Virtual Power Plant (VPP), being capable of providing ancillary services for voltage and frequency control. However, the capability to have these generation facilities participating in Power System Restoration (PSR), following a system black out, needs to be researched namely in the identification of the advanced control functionalities and requirements that wind farms must incorporate in order to actively participate in the restoration procedure.

\section{A New Solution for PSR}

Within the new generation paradigm presented, a combined approach to restoration procedures that includes utility scale wind farms connected to the transmission level and DG units connected into the distribution grid is clearly regarded as an added value. In this paper, the analysis will be focused mainly on the identification of the requirements and procedures to exploit large offshore wind parks connected at transmission level, since restoration using DG units connected at distribution level has already been a matter of thoughtful research [3-4].

Considering the advanced features that power energy converters installed in utility WF may provide (namely: reactive power/voltage control, inertial emulation and primary frequency regulation capabilities), it is possible then to exploit these facilities to support PSR [9-10].

By developing and exploiting these advanced control capabilities of utility scale wind parks, it is possible to include them earlier in the PSR process contributing, for example, to the control of the high reactive power produced by unloaded high voltage long transmission lines, followed by ramping up in a fast manner of some wind generation when load is stepping up. This coordinated approach will represent a significant improvement regarding the reduction of the restoration times, leading to smaller economic and social costs.

Although service restoration requires the availability of synchronous units with black start capability (hydraulic units or gas turbines), the development of the restoration process requires the participation of other type of units that might not be ready to run, due to the large volume of renewables integration existing prior to the blackout. Therefore, in order to reduce the restoration times, plants such as large WF that can be quickly connected to the grid (even those built in offshore areas and connected to the grid through HVDC technology) need to be considered in the overall restoration procedure. Therefore, the key challenges of this approach are identifying the rules and conditions for large offshore wind parks integration in the PSR plan, as well as the rules that will enable the increase of restored load and restoration time reduction.

For that purpose, in this research one has developed restoration sequences comparing strategies implemented over a VHV AC network with conventional generation (thermal units and hydraulic units) for two cases:

1) Without the participation of wind generation;

2) With a large offshore WF participating the restoration plan.

The most elementary HVDC offshore transmission system consists on a WF connected to a rectifier, a DC power transmission cable and an inverter connecting the DC system to the mainland AC system. Depending on the types of solid state switches used both for the rectifier and for the inverter, two different HVDC solutions are possible: (1) HVDC line commutated converter (HVDCLCC) if thyristor valves are used or (2) HVDC voltage source converter (HVDC-VSC) if IGBT valves are used. Although HVDC-LCC is a robust solution used for many years for bulk power transmission, HVDC-VSC seems to be the most promising technology for large-scale offshore WF integration since it enables the independent control of active and reactive power, voltage support at the offshore WF site and even allows black-start procedures.

In order to test these restoration plans, EUROSTAG was used as the simulation platform. Dynamic models for the different generator types, including their voltage and frequency regulation loops (plus the over and under excitation limiters) were adopted, exploiting the available models from the EUROSTASG library [12]. The offshore wind park was modelled using macroblock advanced modelling tool and connected to the grid using a dynamic injector $(\mathrm{P}, \mathrm{Q})$. A similar approach can be adopted for onshore WF.

\section{Characteristics and Models of the Wind Energy Converters and HVDC-VSC Stations}

Large offshore WF are assumed to be connected to shore through an HVDC link. The WF considered is equipped with Permanent Magnet Synchronous Generators (PMSG) that are connected to the onshore $\mathrm{AC}$ grid by an $\mathrm{AC} / \mathrm{DC} / \mathrm{AC}$ converter. A single equivalent generator is used to model the offshore WF.

In order to endow offshore WF with the capability of participating in primary frequency control services, it is 
necessary to introduce additional control functionalities in the HVDC-VSC stations. It is important to mention that the main objective of the additional control is to make possible that the offshore DC connected WF contributes to mainland primary frequency regulation.

In this research it was assumed that the solution described in [11] was implemented, such that frequency changes in the mainland grid are proportionally converted into DC voltage changes, through a droop control approach implemented at the onshore HVDC station. Afterwards these DC voltage changes are converted by the offshore HVDC station into frequency changes, exploiting another droop control approach. Then it is assumed that wind generators can be operated on a deloaded maximum power extraction curve to be able to provide primary frequency control following a similar approach to the one described in [9-10].

The frequency droops for the onshore and offshore converters can be adjusted centrally in a coordinated way by the system operators, according to the specificities of the AC onshore system operating conditions.

Regarding the provision of reactive power / voltage control, the HVDC-VSC is assumed to be capable to provide such functionality, behaving in a similar way to a STATCOM, i.e. injecting reactive power proportionally to the terminal voltage changes. For the case of the offshore WF, the full reactive capacity of the HVDC VSC converter was made available to support the PSR procedure (after being connected to the grid) providing an extremely fast and valuable control capability to the grid, by absorbing the excess of reactive power that may exist in the first steps of the restoration scheme, namely due to the energization of unloaded transmission lines. The macroblock scheme used to model the dynamic behaviour of this offshore WF and its HVDC interconnection is described in the next figure.

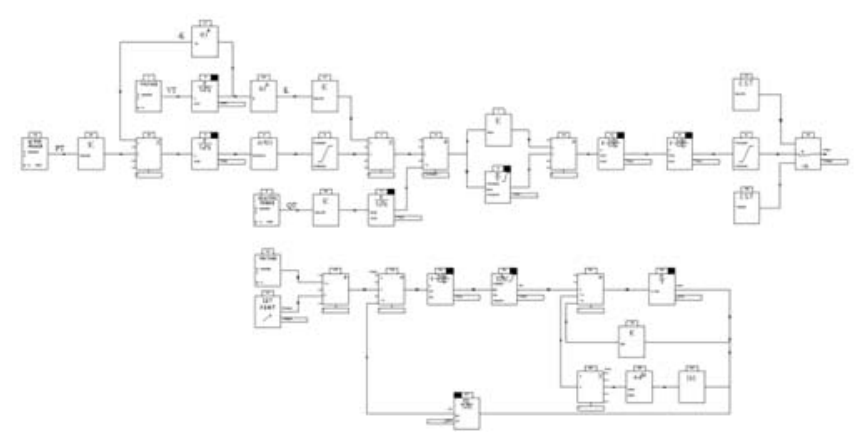

Figure 1 - Macroblock model of the offshore WF

\section{Identifying PSR Sequences}

The identification of the sequence of actions that need to be taken in order to restore the system to its pre-blackout state (namely picking up all the load previously connected) was developed using a step by step procedure as follows:

- Energize the bus of the generator that has black start capability and that has adequate capacity to absorb reactive power generated by unloaded transmission lines following its energization;

- Energize the HV lines, while keeping control of the voltage on the grid using the generators reactive power absorption capability;

- Connect some steps of load by energizing feeders in substations already connected to the grid.

- Keep on connecting other generators following the energization of their auxiliary services and after a minimum time required to have the generators ready to be synchronized with the grid.

While developing this sequence the following operational restrictions were kept under control:

- Frequency excursions in the range of $[-0,5 ;+0,2]$ $\mathrm{Hz}$

- Maximum overvoltage 1,1 p.u. during $5 \mathrm{~s}$.

- Minimal time between operations:

- Start-up time thermal units: 20 minutes.

- Start-up time hydraulic units: 5 minutes.

- Grid operations: 40 seconds.

These values can be adjusted case by case, according to the grid operational characteristics and protection systems.

When including wind generation in the PSR, identifying the timings and step volumes of wind power connection becomes one of the major concerns of all this procedure. Simultaneously, the need of having specific requirements over existing wind turbines, namely the capability of deloading operation and provision of primary frequency regulation needs to be addressed in detail. A typical approach consists in exploiting WF below its maximum power extraction capability, hence creating a spinning reserve margin. Additionally, the use of a local control loop at the wind turbine level, whose input variable is the frequency deviation, allows the control of the turbine power output for primary frequency regulation purposes.

\section{The Test Systems}

The test system used to evaluate and identify the possibility of having WF participating in the PSR procedure is described in next figure. It is composed by 22 buses, 4 conventional generators using synchronous machines, 2 hydraulic and 2 thermal-fossil steam units. When evaluating the test case including the offshore WF, it was assumed its connection to bus 12 . The nominal voltage of the grid is $380 \mathrm{kV}$. 


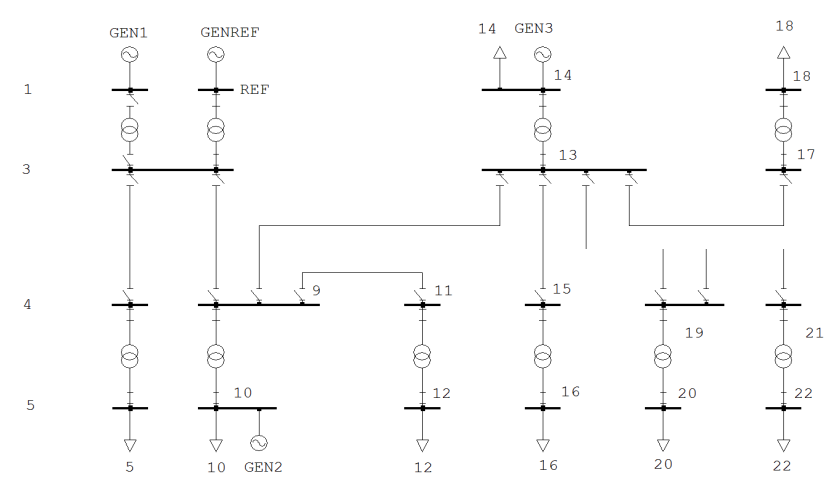

Figure 2 - Single line diagram of the test system

Table I -Main characteristics of the generators

\begin{tabular}{|c|c|c|c|c|c|c|}
\hline \multicolumn{7}{|c|}{ Synchronous machines } \\
\hline Name & Unit type & $\begin{array}{l}\text { Connection } \\
\text { node }\end{array}$ & $\begin{array}{l}\text { S } \\
\text { (MW) }\end{array}$ & $\begin{array}{l}\text { Voltage } \\
\text { regulator }\end{array}$ & $\begin{array}{l}\text { Speed } \\
\text { Governor }\end{array}$ & $\begin{array}{l}\text { Under- } \\
\text { excitation } \\
\text { limiter }\end{array}$ \\
\hline Genref & Hydraulic & REF & 158 & $\begin{array}{l}\text { DC1A } \\
{[11]} \\
\end{array}$ & $\begin{array}{l}\text { GovHyd } \\
\text { [12] }\end{array}$ & $\begin{array}{l}\text { UEL2 multi- } \\
\text { segment [11] }\end{array}$ \\
\hline Gen1 & Thermal & 1 & 192 & $\begin{array}{l}\text { DC1A } \\
{[11]}\end{array}$ & $\begin{array}{l}\text { Gover } \\
{[13]}\end{array}$ & $\begin{array}{l}\text { UEL2 multi- } \\
\text { segment [11] }\end{array}$ \\
\hline Gen2 & Hydraulic & 10 & 231.6 & $\begin{array}{l}\text { DC1A } \\
{[11]}\end{array}$ & $\begin{array}{l}\text { GovHyd } \\
{[12]}\end{array}$ & $\begin{array}{l}\text { UEL2 multi- } \\
\text { segment [11] }\end{array}$ \\
\hline Gen3 & Thermal & 14 & 384 & $\begin{array}{l}\text { DC1A } \\
{[11]}\end{array}$ & $\begin{array}{l}\text { Gover } \\
{[13]}\end{array}$ & $\begin{array}{l}\text { UEL2 multi- } \\
\text { segment [11] }\end{array}$ \\
\hline
\end{tabular}

Detailed data about the characteristics of the lines, transformers and load can be obtained upon request. The main characteristics of the conventional generators (nominal power, unit type, type of voltage and speed regulators) are described in the previous table.

It was considered that the all substation load is fully reestablished when we reach $90 \mathrm{MW}$ and 30Mvar at each bus load.

The line connecting to the off-shore HVDC VSC is considered to be long. After energizing the HVDC grid, the wind power generation pick-up was incremented by steps, connecting clusters of wind generators every 30 seconds.

In this case, it is assumed that the onshore HVDC-VSC is energized after the blackstart of some synchronous units followed by the energyzation of the path that allows the synchronization of the onshore HVDC-VSC station. Thereafter, the HVDC link is also assumed to become energized thus allowing the blackstart of the offshore HVDC-VSC station, which is followed by the step by step connection of offshore wind generators.

\section{Power System Restoration Sequences}

Two PSR sequences were identified, following the rules and restrictions described before for the 2 cases: a) without wind generation and b) with offshore wind generation.

Case a)
First it is essential that the crank up power for the generators is provided to those units that are not energized and don't have backstart capability. By then, the first action is to energize the bus1 providing crank-up power to the generator Gen1. Since Genref can't absorb the extra reactive power created by connecting a line, the restoration process can't go further until Gen1 is online. After 20minutes the thermal unit Gen 1 is operational and the system restoration can now resume, the lines 3-9 and 9-13 breakers are closed leading power to the buses 10 and 14 where the hydraulic unit Gen 2 and thermal unit Gen3 are installed. The crank-up power is given to these units and they can now begin the start-up process. During the time it takes for these units to become operational, the loads in the energized area of the grid are picked up in small increments, avoiding frequency deviation below $49.5 \mathrm{~Hz}$. As soon as Gen2 is online, the lines 3-4 and 1317 breakers are closed and a new sequence of load pick up is established, then the lines 13-19 and 19-21 are closed and another sequence of load pick up is done until Gen3 is operational. With this unit online that has the highest rated power in the system, the rest of the power grid can be energized, the line 9-11 (that is the longest and consequently the one that creates most reactive power) can now be closed, followed after by the line 1315. The final step is this restoration plan is the final load pick up and with this providing power to the rest of the consumers and finalising the power system restoration sequence.

The PSR sequence of events that was identified for case a) is described in a synthetic manner in the table II.

Table II - PSR sequence for case a)

\begin{tabular}{|c|c|c|c|c|c|}
\hline $\begin{array}{c}\text { Time } \\
(\mathrm{s})\end{array}$ & Event & $\begin{array}{c}\text { Time } \\
(\mathrm{s})\end{array}$ & Event & $\begin{array}{c}\text { Time } \\
(\mathrm{s})\end{array}$ & Event \\
\hline 0 & Close line 3-4 & 1700 & $\begin{array}{c}\text { Load pick-up } \\
18\end{array}$ & 2220 & $\begin{array}{c}\text { Load pick-up } \\
22\end{array}$ \\
\hline 1200 & Start-up Gen1 & 1740 & Load pick-up 5 & 2260 & $\begin{array}{c}\text { Load pick-up } \\
20\end{array}$ \\
\hline 1240 & Close line 3-9 & 1780 & $\begin{array}{c}\text { Load pick-up } \\
18\end{array}$ & 2300 & $\begin{array}{c}\text { Load pick-up } \\
18\end{array}$ \\
\hline 1280 & Close line 13-9 & 1820 & $\begin{array}{c}\text { Load pick-up } \\
10\end{array}$ & 2480 & Start-up Gen3 \\
\hline 1320 & $\begin{array}{c}\text { Load pick-up } \\
14\end{array}$ & 1860 & $\begin{array}{c}\text { Close line 13- } \\
19\end{array}$ & 2520 & Close line 9-11 \\
\hline 1360 & $\begin{array}{c}\text { Load pick-up } \\
10\end{array}$ & 1900 & $\begin{array}{c}\text { Close line 19- } \\
21\end{array}$ & 2560 & $\begin{array}{c}\text { Close line 13- } \\
15\end{array}$ \\
\hline 1400 & $\begin{array}{c}\text { Load pick-up } \\
14\end{array}$ & 1940 & $\begin{array}{c}\text { Load pick-up } \\
20\end{array}$ & 2600 & $\begin{array}{c}\text { Load pick-up } \\
12\end{array}$ \\
\hline 1440 & $\begin{array}{c}\text { Load pick-up } \\
10\end{array}$ & 1980 & $\begin{array}{c}\text { Load pick-up } \\
22\end{array}$ & 2640 & $\begin{array}{c}\text { Load pick-up } \\
16\end{array}$ \\
\hline 1480 & $\begin{array}{c}\text { Load pick-up } \\
14\end{array}$ & 2020 & $\begin{array}{c}\text { Load pick-up } \\
20\end{array}$ & 2680 & Load pick-up 5 \\
\hline 1540 & $\begin{array}{c}\text { Start-up Gen2 } \\
2060\end{array}$ & $\begin{array}{c}\text { Load pick-up } \\
22\end{array}$ & & \\
\hline 1580 & Close line 3-4 & 2100 & $\begin{array}{c}\text { Load pick-up } \\
20\end{array}$ & & \\
\hline 1620 & $\begin{array}{c}\text { Close line 13- } \\
17\end{array}$ & 2140 & $\begin{array}{c}\text { Load pick-up } \\
22\end{array}$ & & \\
\hline 1660 & Load pick-up 5 & 2180 & $\begin{array}{c}\text { Load pick-up } \\
22\end{array}$ & & \\
\hline & & & & \\
\hline
\end{tabular}

Next figures describe system voltage and frequency evolution during the PSR sequence tested in this case. 


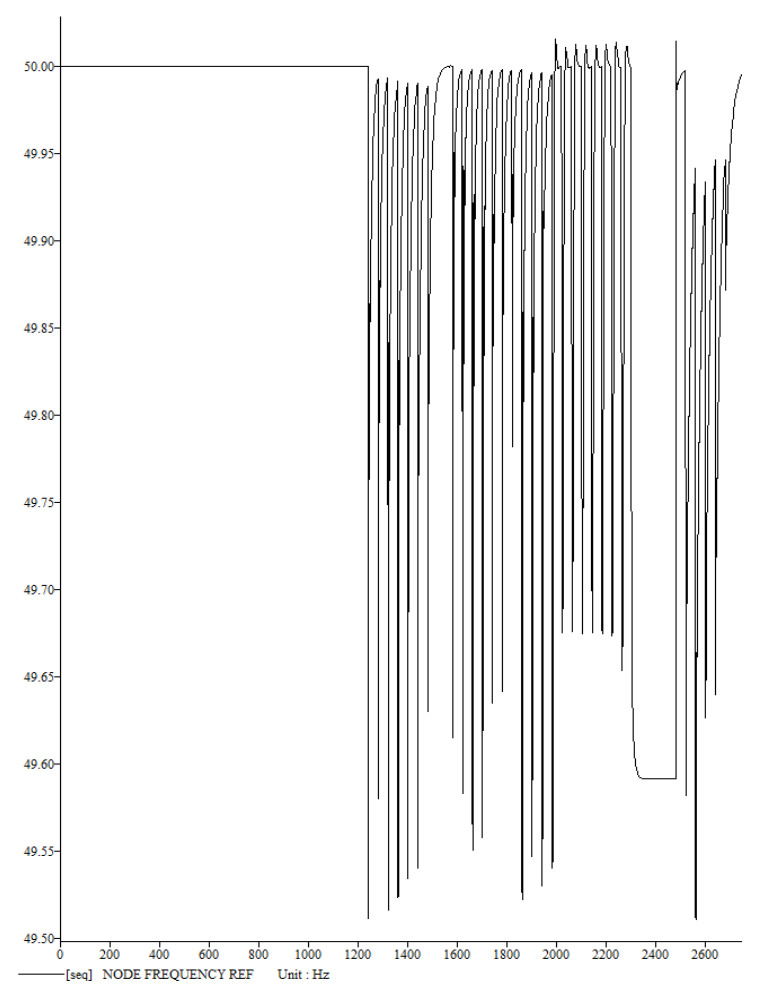

Figure 3 - Behaviour of frequency during the PSR for case a)

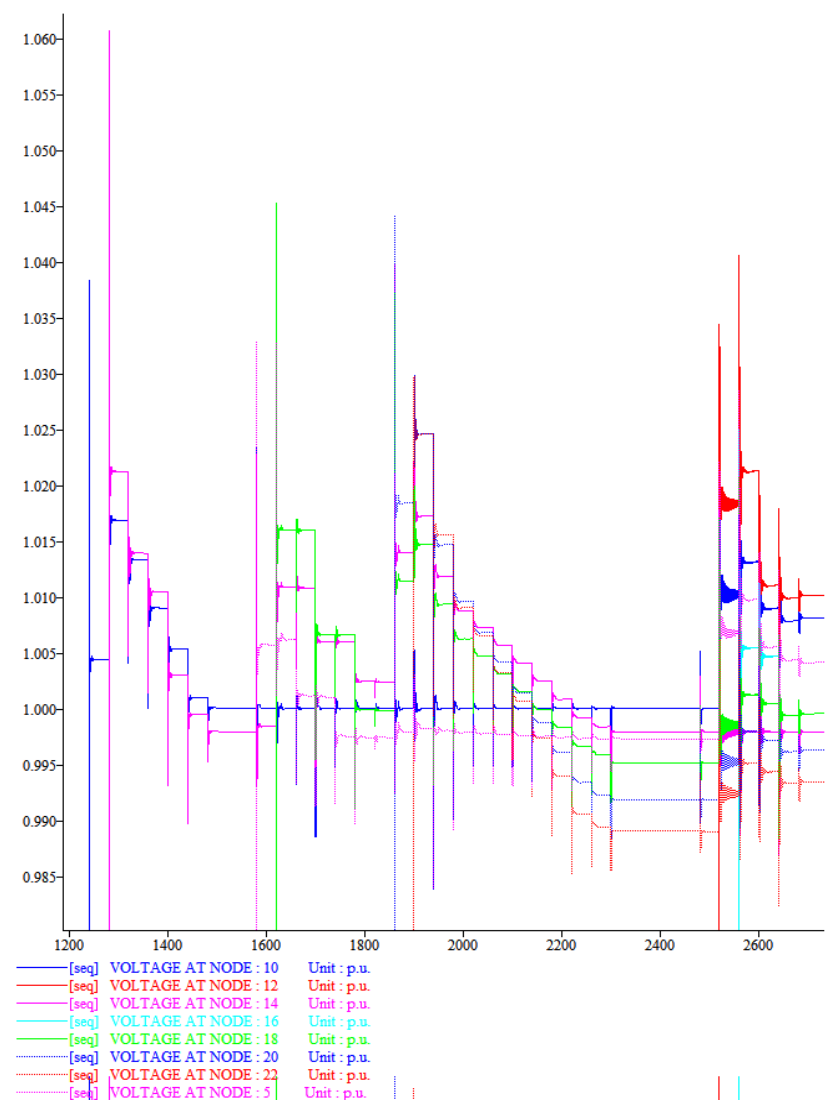

The total system restoration time (picking up the whole $720 \mathrm{MW}$ ) was for this case 46.6 minutes. The not served energy to the consumers during the PSR procedure was in the amount of $148.75 \mathrm{MW} / \mathrm{h}$.

The most critical issues that had to be tackled during the PSR procedure are the following:

- When the load increments are lower in the same sequence, this is due to the fact that the system reached a point where it cannot withstand more load without the frequency to decline beyond the limit. The generation units are working close to their limit.

- At 2340 s it's clearly visible in the frequency figure that the generation unit reached their rated power. That being said, after the load increment the frequency does not come back to $50 \mathrm{~Hz}$ but remains higher than $49.5 \mathrm{~Hz}$. After Gen 3 is operational the frequency is restored to its normal value.

Case b)

When developing this PSR sequence additional restrictions were included, in what concerns the offshore WF contribution. These restrictions were related with minimal time between operations:

- Start-up time wind generation units: 40 seconds

- Wind generation power pick-up: 30 seconds

The system restoration process with offshore WF is similar in the beginning to case a), meaning that only after Gen2 becomes operational some changes occur in the restoration process. Until that moment the system cannot withstand the reactive power generated by the line 9-11. So, when Gen2 is online the restoration process resumes by closing the line 9-11, and with this connecting the offshore wind farm with the power grid. When the wind generation starts-up, it involves a sequence of connection of 3 power clusters, leading to the power injections into the grid, picking up power in the wind farm to $8 \%$ of its rated power, corresponding to $40 \mathrm{MW}$. After this, the line 13-19 is closed and load 20 is picked up, then the line 1921 is also closed and the load 22 is picked up. Since the line 19-21 is the smallest, it was decided to energize this segment of the grid first, as the losses are smaller and the power picked up is higher ( two loads in the system and so a higher amount of power is provided in the PSR. A new sequence of power increase in the system is performed by injecting more power from the wind farm, connecting more wind turbines to the grid. Then, the lines 13-17 and 3-4 are closed, noting that between these events the loads that are connected to the buses 18 and 5 are picked up. A final power injection by the wind farm is 
made, connecting a total 16 wind turbines, with a rated power of $2 \mathrm{MW}$ each, providing more $32 \mathrm{MW}$ to the system. This value is achieved in two distinct power clusters, in order to respect the frequency increase limit. After this, more load is picked up until Gen3 is operational. Finally, line $13-15$ is closed and the remaining loads are full energized.

The PSR sequence of events that was identified for case b) is described in a synthetic manner in the next table.

\begin{tabular}{|c|c|c|c|c|c|}
\hline $\begin{array}{l}\text { Time } \\
\text { (s) }\end{array}$ & Event & $\begin{array}{l}\text { Time } \\
\text { (s) }\end{array}$ & Event & $\begin{array}{l}\text { Time } \\
\text { (s) }\end{array}$ & Event \\
\hline 0 & Close line 3-4 & 1680 & $\begin{array}{l}\text { E12 power pick- } \\
\text { up }\end{array}$ & 2190 & $\begin{array}{l}\text { E12 power pick } \\
\text { up }\end{array}$ \\
\hline 1200 & Start-up Gen1 & 1720 & Load pick-up 12 & 2220 & $\begin{array}{l}\text { E12 power pick } \\
\text { up }\end{array}$ \\
\hline 1240 & Close line 3-9 & 1760 & Load pick-up 12 & 2250 & Load pick-up 5 \\
\hline 1280 & Close line 13-9 & 1800 & Close line 13-19 & 2290 & Load pick-up 22 \\
\hline 1320 & Load pick-up 14 & 1840 & Load pick-up 20 & 2330 & Load pick-up 10 \\
\hline 1360 & Load pick-up 10 & 1880 & Close line 19-21 & 2370 & Load pick-up 20 \\
\hline 1400 & Load pick-up 14 & 1920 & Load pick-up 22 & 2410 & Load pick-up 18 \\
\hline 1440 & Load pick-up 10 & 1960 & $\begin{array}{l}\text { E12 power pick- } \\
\text { up }\end{array}$ & 2450 & Load pick-up 20 \\
\hline 1480 & Load pick-up 14 & 1990 & $\begin{array}{l}\text { E12 power pick- } \\
\text { up }\end{array}$ & 2490 & Start-up Gen3 \\
\hline 1540 & Start-up Gen2 & 2030 & Close line 13-17 & 2530 & Close line $13-15$ \\
\hline 1580 & Close line 9-11 & 2070 & Load pick-up 18 & 2570 & Load pick-up 16 \\
\hline 1620 & Start-up E12 & 2110 & Close line 3-4 & 2630 & Load pick-up 22 \\
\hline 1650 & $\begin{array}{l}\text { E12 power pick- } \\
\text { up }\end{array}$ & 2150 & Load pick-up 5 & & \\
\hline
\end{tabular}

Next figures describe the way how the frequency and voltage has changed in the system during the PSR procedure.

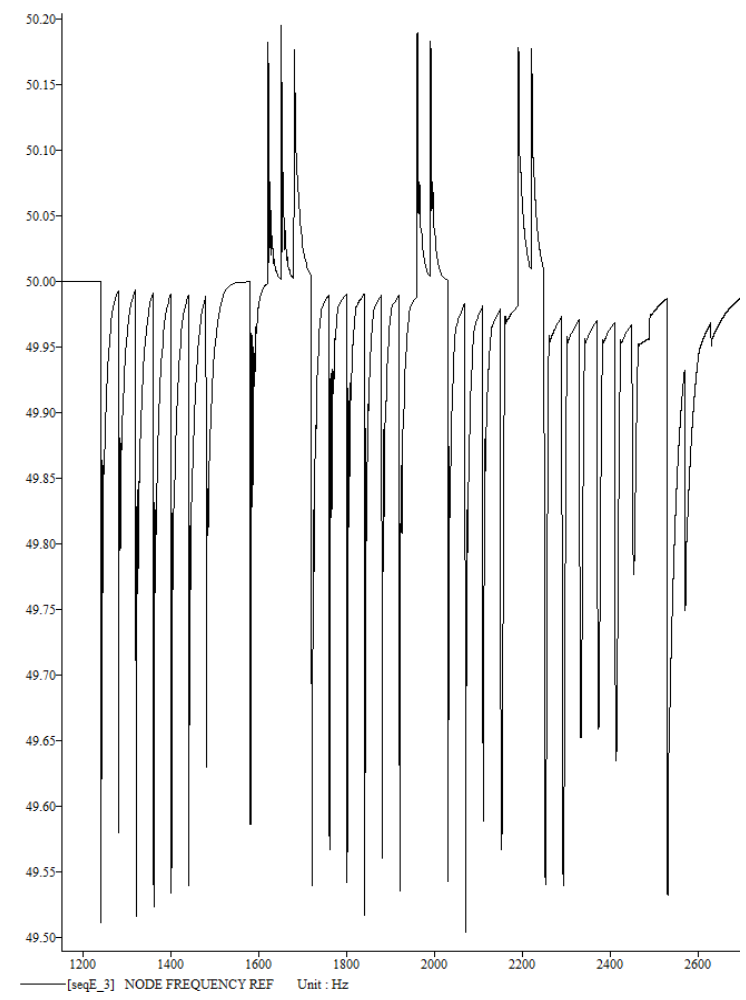

Figure 5 - Behaviour of frequency during the PSR for case b)

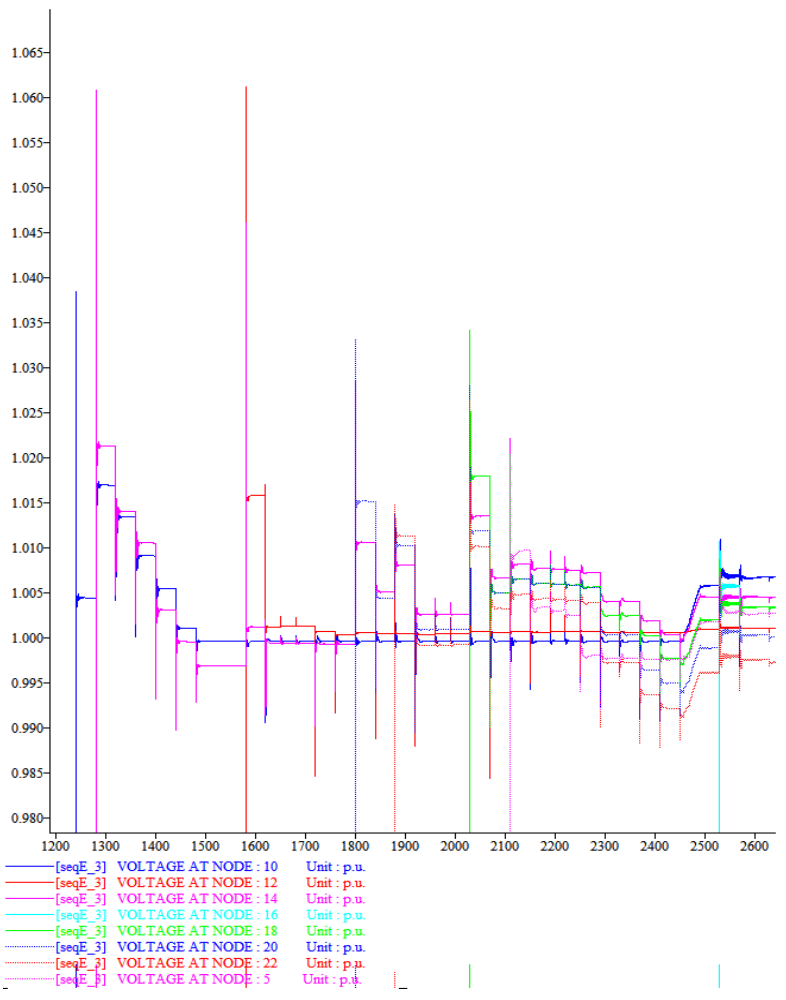

Figure 6 - Behaviour of bus voltages during the PSR for case b)

In this case the wind generators of offshore wind farm were set with a deload of about $10 \%$. During the PSR procedure, the level of deloading of the wind generators can be increased in order to increase their participation in primary frequency control. The participation of these wind generation units in the primary frequency and voltage control of the grid can be observed in figures 7,8 and 9.

Regarding figure 7, the step increases and the changes in wind power generation correspond to the connection of the cluster of wind generators and their participation in frequency regulation. These values appear as negative, because the WF is represented in EUROSTAG as a power injector (negative load). These negative injections of power correspond to positive injections of active power into the HV grid. From figure 8, one can observe that the VSC of the offshore WF was contributing significantly to voltage control, by responding in a very fast manner to reactive power increases that take place when new lines are being energized. In this case the injections of reactive power are positive in the figure, but correspond to absorption of capacitive reactive power from the grid. This provides an interesting contribution to ease the PSR procedure in what concerns voltage control on the grid. The deloading of the turbine systems creates a power reserve that can be rapidly injected in the system to assist frequency control. In this study we considered a $10 \%$ deloading of the active power. 


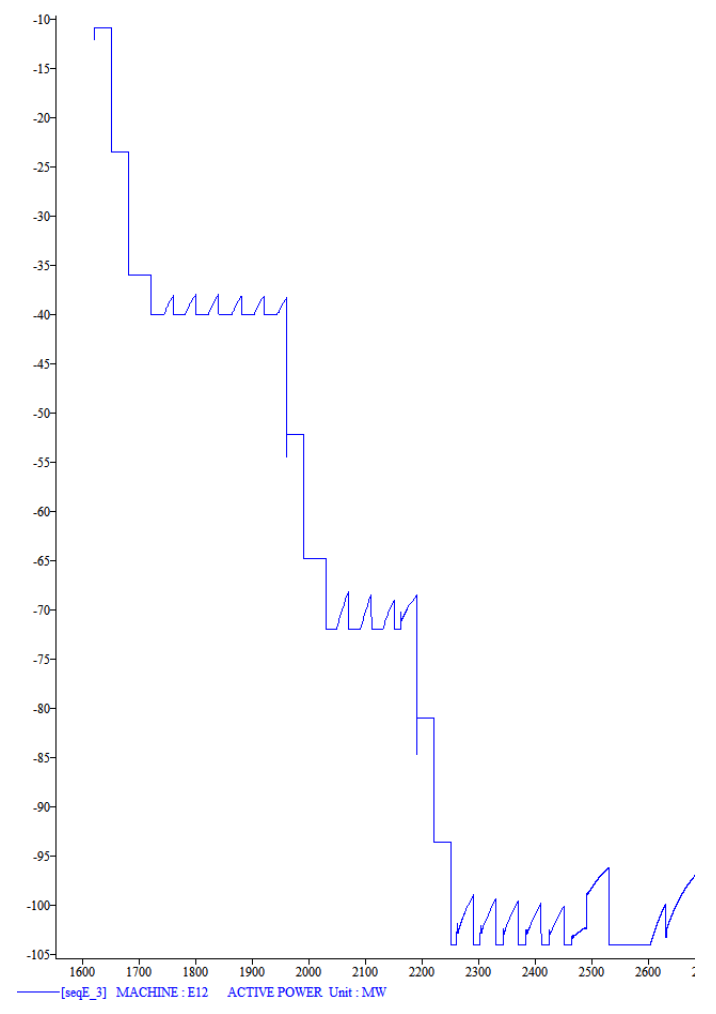

Figure 7 - Active power generation from the WF.

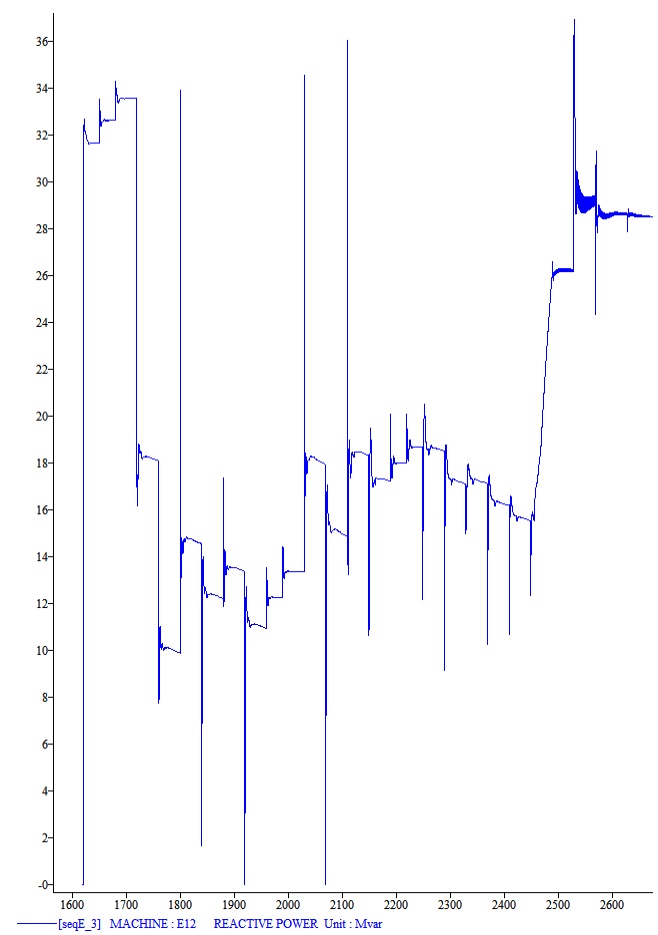

Figure 8 - Reactive power generation from the WF converter

Figure 9, shows in detail the response of the WF to frequency variations in the time frame between 1720 and
1800 seconds. In this period, there are three load pickups, decreasing significantly the systems frequency, and the maximum power available in the WF is $40 \mathrm{MW}$.

When the frequency is at $50 \mathrm{~Hz}$, and considering the defined deloading, the WF will inject $36 \mathrm{MW}$. The decrease in the frequency leads the WF to inject the power reserve, hence the rapid variations seen. As the frequency is restored the WF injected power will decrease, not reaching the minimum value because the frequency will not reach its nominal value in time for the next load pickup.
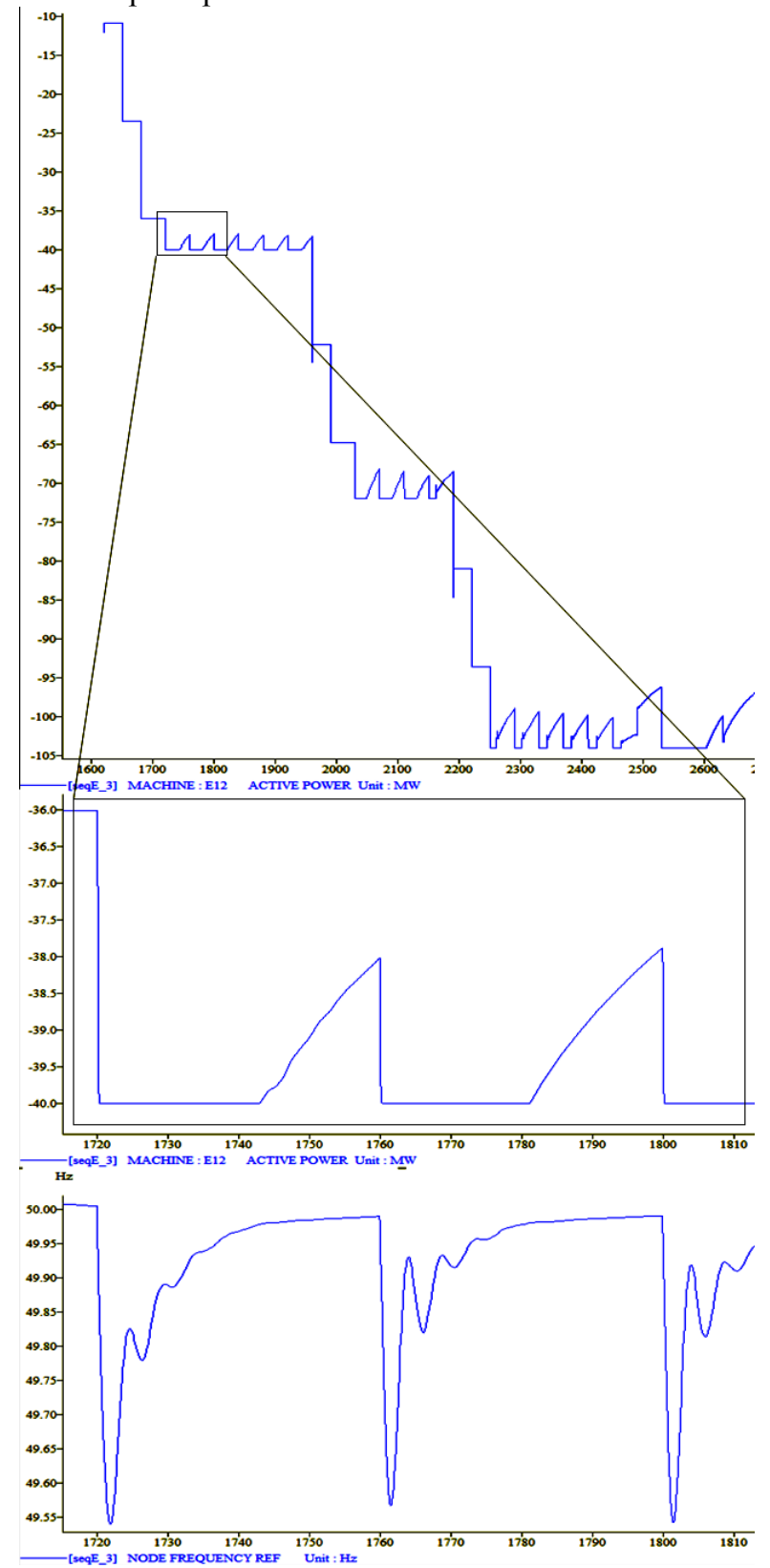

Figure 9 - WF active power response to the system frequency The total system restoration time (for $720 \mathrm{MW}$ ) was, for this case, 43.8 minutes. The not served energy to the 
consumers during the PSR procedure was in the amount of $140.75 \mathrm{MW} / \mathrm{h}$.

Next figure allows comparing the way how the two PSR procedures evolved in time.

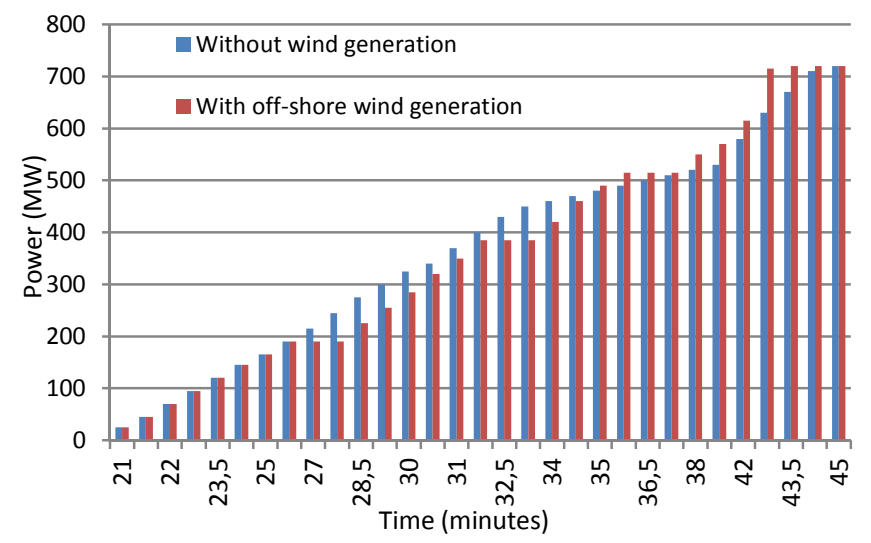

Figure 10 - Load pick-up versus time on the system during the PSR

From figure 9, one can observe that after the energization of the offshore farm, the load pick up in the system is faster than in the scenario where no WF exists. This is due to the fact that the WF has a very large reactive and active power response, while in the scenario b) this response is splint by several conventional generation units that take some time to be connected.

\section{Conclusions}

This paper provides an initial study on the exploitation of large scale offshore WF within the development of PSR plans within a transmission grid. The large scale integration of renewables based generation lead to the displacement of synchronous units, which might not be ready to run in a short time to fully support the restoration phase. The increasing installation of offshore WF with high regulation capabilities provides an alternative to be considered in the initial phases of the restoration procedure. First, the energization of the busbar where the onshore HVDC-VSC station is connected provides additional voltage control capability, which is a key issue in the initial phase of the restoration process as a result of the energization on long transmission lines. Afterwards, the exploitation of a communication free control strategy to make offshore WF participation in primary frequency regulation provides also frequency regulation capability to the mainland grid being restored, which is also a key contribution provided the reduced inertia to provide system stability following load reconnection.

Further research is however still required to optimize the restoration sequence.

\section{References}

[1] Directive 2009/28/EC of the European Parliament and of the Council of 23 April 2009 on the promotion of the use of energy from renewable sources and amending and subsequently repealing Directives 2001/77/EC and 2003/30/ EC

[2] http://teeic.anl.gov/er/wind/restech/scale/index.cfm

[3] Andersson, G., et al. "Causes of the 2003 major grid blackouts in North America and Europe, and recommended means to improve system dynamic performance." Power Systems, IEEE Transactions on 20.4 (2005): 1922-1928.

[4] Moreira, C. L.; Resende, F. O.; Lopes, J. A. P.; , "Using Low Voltage MicroGrids for Service Restoration," Power Systems, IEEE Transactions on , vol.22, no.1, pp.395-403, Feb. 2007.

[5] Fernanda Resende, Nuno Gil, Peças Lopes, Service restoration on distribution systems using Multi-MicroGrids , European Transactions on Electrical Power, vol.21, no.2, pp.1327-1342, March, 2011

[6] M. M. Adibi and L. H. Fink, "Special considerations in power system restoration." IEEE Transactions on Power Systems, vol. 7, no. 4, pp. 1419-1427, November 1992

[7] J. J. Ancona, "A framework for power system restoration following a major power failure." IEEE Transaction on Power Systems, vol. 10, no. 3, pp. 1480-1485, August 1995

[8] M. M. Adibi and L. H. Fink, "Power system restoration planning." IEEE Transactions on Power Systems, vol. 9, no. 1, pp. 22-28, February 1994

[9] G. Lalor, A. Mullane, M. O'Malley, "Frequency control and wind turbine technologies," IEEE Trans. on Power Systems, Vol. 20, No. 4, pp. 1905-1913, November 2005

[10] R. G. de Almeida, and J. A. Peças Lopes, "Participation of doubly fed induction wind generators in system frequency regulation," IEEE Trans. on Power Systems, Vol. 22, No. 3, pp. 944-950, August 2007

[11] B. Silva, C. L. Moreira, L. Seca, Y. Phulpin, and J. A. Pecas Lopes, "Provision of Inertial and Primary Frequency Control Services Using Offshore Multiterminal HVDC Networks," Sustainable Energy, IEEE Transactions on, vol. 3, no. 4, pp. 800808,2012

[12] "IEEE Recommended Practice for Excitation System Models for Power System Stability Studies." IEEE Std 421.5-2005 (Revision of IEEE Std 421.5-1992): 0_1-85. 